\title{
Research
}

\section{Body weight reduction to avoid the excess risk of type 2 diabetes}

\begin{abstract}
Background

It is recognised that people who are overweight have an increased risk of diabetes but the quantitative relationship is less well recognised and the extent of weight reduction needed to avoid the excess risk of diabetes through being overweight, is not well appreciated
\end{abstract}

\section{Aim}

To derive a simple clinical algorithm to calculate the weight change needed to achieve a specified goal for reduction of body mass index (BMI, weight/height squared $\left[\mathrm{kg} / \mathrm{m}^{2}\right]$ that would avoid the excess risk of diabetes and quantify the preventive effect.

\section{Design and setting}

Analysis of the results from two large published cohort studies of the incidence of diabetes in relation to BMI.

\section{Method}

Epidemiological data show that the risk of diabetes doubles for every 2.5 unit increase in $\mathrm{BMI}$ above a BMI of $22 \mathrm{~kg} / \mathrm{m}^{2}$ and halves for every 2.5 unit decrease in BMl down to $22 \mathrm{~kg} / \mathrm{m}^{2}$. The risk of diabetes also approximately doubles for every 10 years of age. From these relationships, a simple algorithm was derived to specify a person's weight-reduction goal to avoid the excess risk of diabetes.

\section{Results}

Converting a BMl-reduction goal (for example, 27 $\mathrm{kg} / \mathrm{m}^{2}$ to $22 \mathrm{~kg} / \mathrm{m}^{2}$ ) into a percentage reduction (in this example, 19\%) specifies the same percentage weight reduction (19\%) because, as a percentage, the reduction is independent of height. This percentage can then easily be converted into an absolute risk reduction (in this example, a 75\% reduction in risk).

\section{Conclusion}

The algorithm achieves two objectives: (i) it specifies the weight-reduction goal to reverse a person's excess risk of diabetes due to being overweight, and (ii) it quantifies the risk reduction.

\section{Keywords}

body mass index; overweight; primary care; risk reduction; type 2 diabetes.

\section{INTRODUCTION}

Being overweight increases the risk of type 2 diabetes (hereafter referred to simply as diabetes). An analysis based on the results from two large cohort, one performed on males ${ }^{1}$ and the other on females, ${ }^{2}$ studies showed that, above an 'optimal' body mass index (BMI, weight in $\mathrm{kg}$ divided by height in metres squared) value of $22 \mathrm{~kg} / \mathrm{m}^{2}$, a 2.5 unit increase approximately doubles the risk of developing diabetes, regardless of initial BMI levels. This is shown in Figure 1, which is derived from a logistic regression model based on data from the two cohort studies. The proportional risk reduction of developing diabetes is $1-\left(0.5^{\times / 2.5}\right)$, where $x$ is the BMI reduction. So, for example, for a person with a BMl of $27 \mathrm{~kg} / \mathrm{m}^{2}$, the $\mathrm{BMl}$-reduction goal is $5 \mathrm{BMI}$ units and the diabetes relative risk reduction for this $\mathrm{BMI}$ unit reduction is:

$1-\left(0.5^{5 / 2.5}\right)=1-\left(0.5^{2}\right)=1-0.25=0.75$, or $75 \%$.

For a particular person who knows his or her BMI, it is simple to determine the BMIreduction goal (by subtracting 22) but their weight-reduction goal depends on their height. This study aimed to derive a simple clinical algorithm to calculate the weight change needed to achieve a specified BMIreduction goal that would avoid the excess risk of diabetes and quantify the preventive effect.

\section{METHOD}

The incidence of diabetes for males and

NJ Wald, FRCP, FRS, director and professor of environmental preventive medicine; JP Bestwick MSc, lecturer in medical statistics; JK Morris, $\mathrm{PhD}$, professor of medical statistics, Wolfson Institute of Preventive Medicine, Barts and the London School of Medicine and Dentistry, Queen Mary University of London, London.

Nicholas J Wald, Wolfson Institute of Preventive Medicine, Barts and the London School of Medicine females was estimated based on an a $10-$ year risk of diabetes with a BMI of $22 \mathrm{~kg} / \mathrm{m}^{2}$ as 6 per 1000 in males aged 40-75 years and 4 per 1000 in females aged $30-55$ years, derived from a poisson regression of the incidence of diabetes on BMI, using data from each of the two cohort studies. 1,2 There is little or no difference in the risk of diabetes between males and females at a given age (supported by other studies ${ }^{4,5}$ ), but at a given $\mathrm{BMI}$ there is an independent effect of age. Allowing for the different age distribution in the two cohort studies, 1,2 the 10-year incidence of diabetes in males and females combined at a BMl of $22 \mathrm{~kg} / \mathrm{m}^{2}$ and an age of 50-54 years was estimated as 5.268 per 1000

The slope of the regression line, $m$, relating $\mathrm{BMI}$ to age-adjusted relative risk of diabetes in Figure 1 is given by the equation $\log _{10}$ (relative risk) $=m x+c$, where $m=$ $0.1122054, c=-2.469$ and $x$ is BMI. In the cohort study of females, after adjustment for BMI, females aged 60-64 years had a relative risk of 3.4 (95\% confidence interval $[\mathrm{Cl}]=2.5$ to 4.6$)$ compared with females aged 40-44 years; it is likely that a similar pattern exists in males. Given the relative risk of 3.4 and assuming the same in males, the risk of diabetes will be approximately doubled for people 10 years older (relative risk 1.84) compared with a 52-year old (the middle age of the two cohort studies). For a specific age, the relative risk compared with a 52-year old is given by the equation $\log _{10}$ (relative risk) $=$ $0.02657 \times$ age -1.3818 . These two equations

and Dentistry, Queen Mary University of London, Charterhouse Square, London, EC1M 6BQ.

E-mail: n.j.waldaqmul.ac.uk

Submitted: 11 January 2012; Editor's response: 17 February 2012; final acceptance: 8 March 2012 CBritish Journal of General Practice

This is the full-length article (published online 28 May 2012) of an abridged version published in print. Cite this article as: Br J Gen Pract 2012; DOI: 10.3399/bjgp12X649098. 


\section{How this fits in}

Being overweight puts people at increased risk of diabetes. This study shows that the risk doubles for every 2.5 unit increase in body mass index (BMI) above $22 \mathrm{~kg} / \mathrm{m}^{2}$ and estimates the weight reduction goal to avoid excess risk of diabetes from being overweight. This study derived a simple algorithm, which is available as an online 'Beat Diabetes Calculator', to calculate an individual's weight-reduction goal.

were used determine the change in risk for a given change in $\mathrm{BMI}$, which was converted into a person's percentage weight reduction required to achieve a BMI of $22 \mathrm{~kg} / \mathrm{m}^{2}$.

\section{RESULTS}

Table 1 shows the relative risk of developing diabetes, the weight-reduction goal, and the relative and absolute reductions in risk on achieving a weight-reduction goal according to $\mathrm{BMI}$ for a person aged 52 years. The footnotes indicate the calculations necessary to complete the table, given a person's BMI and indicate the calculations necessary for people of different ages. The relative risk estimate increases from 1.0 lat a BMl of $22 \mathrm{~kg} / \mathrm{m}^{2}$ ) to $>30$ (at a BMI $>37 \mathrm{~kg} / \mathrm{m}^{2}$ ). Table 1 shows that a 2.5 unit reduction in BMI in a person with a BMl of $24.5 \mathrm{~kg} / \mathrm{m}^{2}$ would reduce the 10-year risk of diabetes by 5 per 1000 (reducing the risk by 47\%). Figure 2 shows the percentage reduction in risk of diabetes according to percentage weight reduction. A $10 \%$ reduction in weight approximately halves the risk of developing diabetes and a $20 \%$ reduction reduces the according to body mass index, based on results from

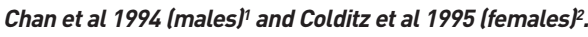

\section{risk by about three-quarters.}

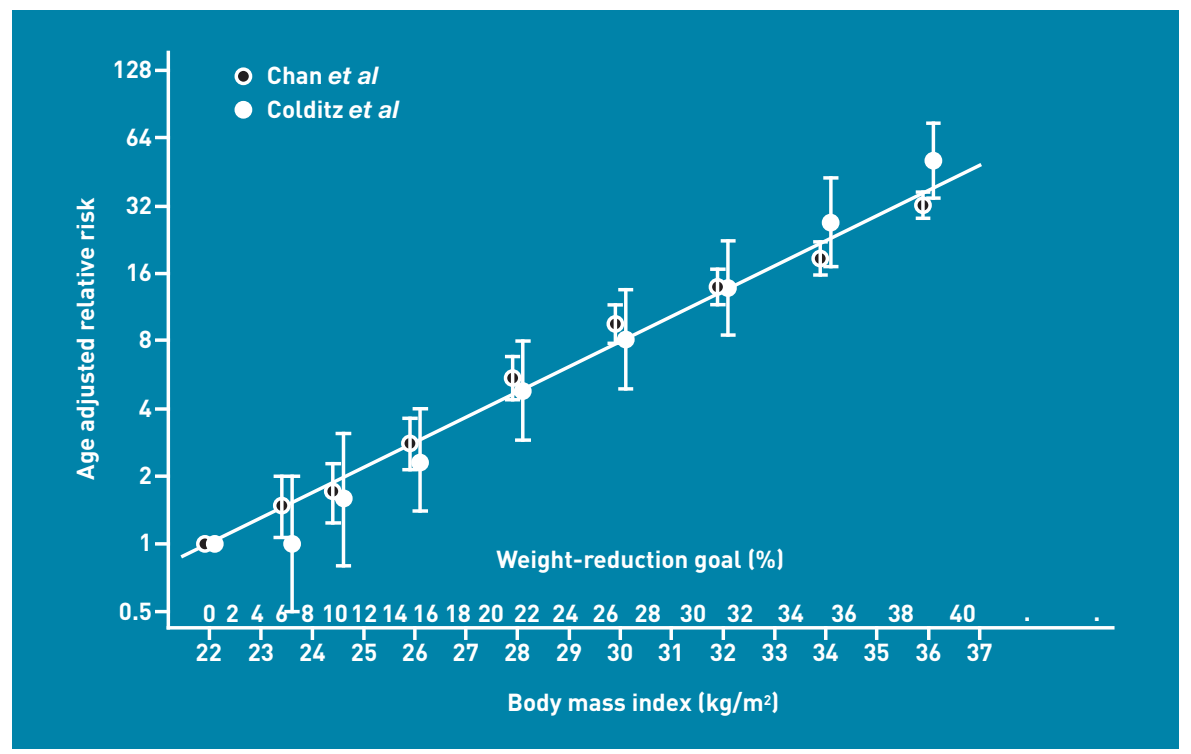

\section{DISCUSSION}

The effect of body weight on the risk of type 2 diabetes is substantial and the preventive effect of reducing weight to achieve a BMI of $22 \mathrm{~kg} / \mathrm{m}^{2}$ is, in turn, considerable. A person's weight-reduction goal can be determined directly without calculating BMI, using the formula: (weight in $\mathrm{kg}$ ) - 22 (height in metres) ${ }^{2}$, but this would have the disadvantage of not using a measure that directly translates into a person's excess risk of diabetes, which is the case with BMI, and not with weight. The proposed approach using percentage of body weight simultaneously informs people of the weight reduction required to avoid the excess risk and the resulting risk reduction.

An approximate conversion of a percentage reduction in the risk of diabetes to an absolute risk reduction can be obtained by dividing the percentage risk reduction by its complement (for example for an $80 \%$ reduction, $80 / 20$ ) and multiplying this by 5 . This yields the absolute risk reduction per 1000 people over 10 years. So, for example, a $75 \%$ risk reduction in a person would achieve an absolute risk reduction of $75 / 25 \times 5$, that is, 15 per 1000 people over 10 years, or $1.5 \%$.

This algorithm is based on data relating to US health professionals, collected about 20 years ago, but this should not affect the generalisability of the algorithm, particularly with respect to the increase in relative risk with increasing BMI. Since the studies were performed, the prevalence of overweight and diabetes has increased. This does not affect the validity of the algorithm, but does increase the scope for prevention through weight reduction.

On average, an increased BMI reflects an excess in fat tissue but this is not always the case. For example, athletes may have a high BMI due to an increased muscle mass rather than an excess in body fat. The weight-reduction goals shown in Table 1 apply to people on average, but are not applicable to individuals who have a high $\mathrm{BMI}$ due to increased muscle rather than excess fat. A simple working rule would be to regard males with a waist circumference of $<85 \mathrm{~cm}$ (33.4 inches) and females with a waist circumference of $<75 \mathrm{~cm}$ (29.5 inches) (approximately the 15th centile among 45-54 year old people in England ${ }^{6}$ as not being at excess risk, regardless of their $\mathrm{BMI}$.

The practical implication of people changing their BMI is difficult to grasp because a person's weight can be reduced but not their height. It is not immediately obvious, for example, what weight reduction 


\begin{tabular}{|c|c|c|c|c|c|c|}
\hline $\begin{array}{l}\text { BMI }\left(\mathrm{kg} / \mathrm{m}^{2}\right) \\
\text { (a) }\end{array}$ & $\begin{array}{c}\text { Excess BMI } \\
>22 \mathrm{~kg} / \mathrm{m}^{2}(\mathrm{~b})\end{array}$ & $\begin{array}{l}\text { Relative risk of } \\
\text { type } 2 \text { diabetes compared } \\
\text { with person with BMI } \\
\text { of } 22 \mathrm{~kg} / \mathrm{m}^{2}(\mathrm{c})\end{array}$ & $\begin{array}{l}\text { Weight reduction } \\
\text { goal to achieve } \\
\text { a BMI of } 22 \mathrm{~kg} / \mathrm{m}^{2} \\
\text { (d) }\end{array}$ & $\begin{array}{c}\text { Relative risk } \\
\text { reduction on achieving } \\
\text { weight reduction goal } \\
\text { (e) }\end{array}$ & $\begin{array}{c}\text { 10-year risk of } \\
\text { diabetes } \\
\text { (per 1000) (f) }\end{array}$ & $\begin{array}{c}\text { Reduction in } \\
10 \text {-year risk of } \\
\text { diabetes following weight } \\
\text { reduction (per 1000) (g) }\end{array}$ \\
\hline 22 & 0 & 1.0 & $0 \%$ & $0 \%$ & 5 & 0 \\
\hline 24.5 & 2.5 & 1.9 & $10 \%$ & $47 \%$ & 10 & 5 \\
\hline 27.0 & 5 & 3.6 & $19 \%$ & $72 \%$ & 19 & 14 \\
\hline 29.5 & 7.5 & 6.9 & $25 \%$ & $85 \%$ & 37 & 32 \\
\hline 32.0 & 10 & 13.2 & $31 \%$ & $92 \%$ & 70 & 65 \\
\hline 34.5 & 12.5 & 25.3 & $36 \%$ & $96 \%$ & 133 & 128 \\
\hline 37.0 & 15 & $>30$ & $41 \%$ & $>97 \%$ & $>157$ & $>153$ \\
\hline 39.5 & 17.5 & $>30$ & $44 \%$ & $>97 \%$ & $>157$ & $>153$ \\
\hline 42.0 & 20 & $>30$ & $48 \%$ & $>97 \%$ & $>157$ & $>153$ \\
\hline
\end{tabular}

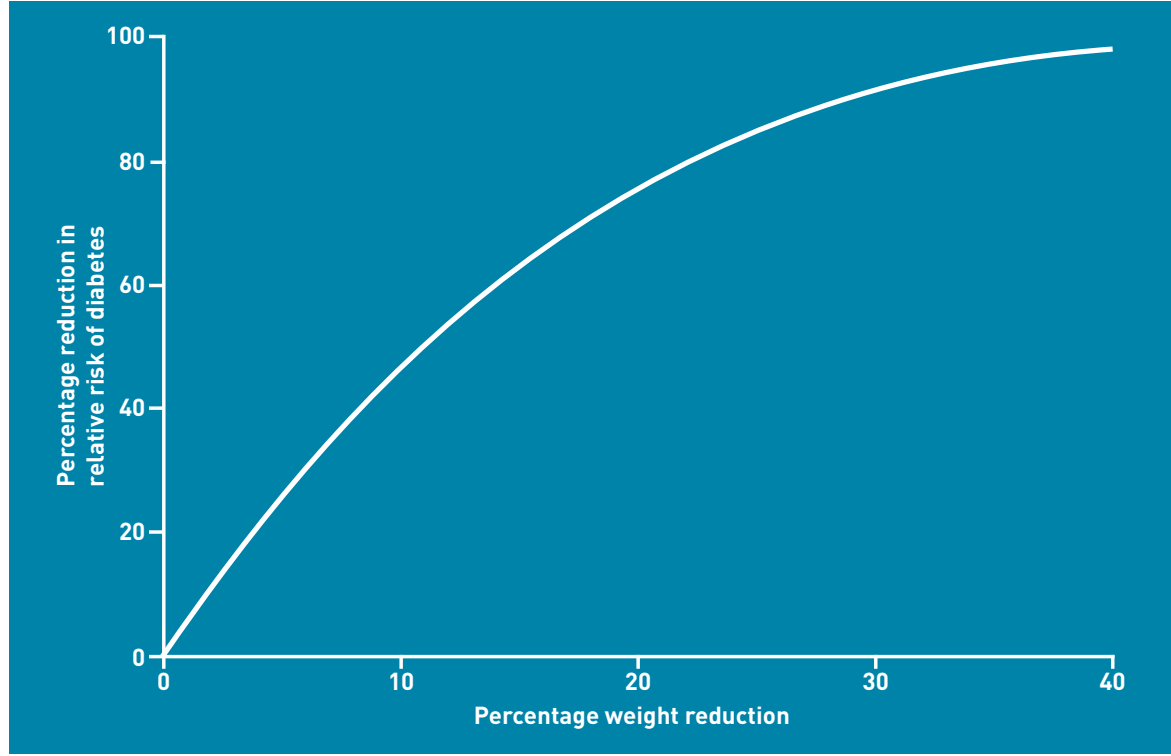

Figure 2. Reduction in risk of diabetes plotted against weight reduction. is needed to move from a BMI of 25 to $22 \mathrm{~kg} / \mathrm{m}^{2}$. It is clearer to know that weight needs to be reduced by $12 \%$, the same proportion as the $\mathrm{BMI}$ reduction, that is, $(25$ $-22) / 25$. This can be converted into an absolute reduction, so, for example, a $70 \mathrm{~kg}$ person with a target weight reduction of
$10 \%$ needs to lose $7 \mathrm{~kg}$. Table 2 sets out the steps involved in determining a person's weight-reduction goal and the consequent reduction in relative risk for type 2 diabetes.

The algorithm is available as an online 'Beat Diabetes Calculator' (http://www.lmsalpha.co.uk/beatdiabetes/) that can be accessed free of charge for general use. It calculates an individual's weight-reduction goal to reverse a person's excess risk of diabetes due to being overweight, and calculates the resulting reduction in their risk of developing diabetes in the next 10 years, presenting this numerically and graphically. It produces a printable report that can be given to each individual and kept with his or her medical records.

Informing a person of their weightreduction goal (rather than their BMIreduction goal), together with a quantitative estimate of the benefits of achieving that goal, should help focus attention on what needs to be known to avoid the substantial risks of diabetes arising from being overweight. Even if a person's weightreduction goal is only partially achieved, the gains are considerable and still worthwhile.

\section{Table 2. Calculating a person's weight-reduction goal}

\begin{tabular}{|c|c|}
\hline Instruction & $\begin{array}{l}\text { Worked example for weight }=75 \mathrm{~kg} \\
(165 \mathrm{lb}) \text { and height }=1.7 \mathrm{~m}(5 \mathrm{ft} 6 \mathrm{in})\end{array}$ \\
\hline 1. Calculate BMI: weight $(\mathrm{kg}) /$ height $^{2}\left(\mathrm{~m}^{2}\right)$ & $75 / 1.7^{2}=75 / 2.89=26 \mathrm{~kg} / \mathrm{m}^{2}$ \\
\hline 2. Calculate BMI-reduction goal (b): subtract 22 & $26-22=4 \mathrm{~kg} / \mathrm{m}^{2}$ \\
\hline $\begin{array}{l}\text { 3. Calculate percentage BMI-reduction goal: } 100 \times \text { BMI-reduction } \\
\text { goal/current BMI. This is the weight-reduction goal }\end{array}$ & $100 \times 4 / 26=15 \%$ \\
\hline $\begin{array}{l}\text { 4. Calculate the absolute weight-reduction goal: current } \\
\text { weight } \times \text { weight-reduction goal }\end{array}$ & $75 \times 15 \%=11 \mathrm{~kg}$ \\
\hline 5. Approximate relative risk reduction for type 2 diabetes: $1-0.5^{0 / 25}$ & $1-0.5^{4 / 2.2}=67 \%$ \\
\hline
\end{tabular}




\section{REFERENCES}

1. Chan JM, Rimm EB, Colditz GA. Obesity, fat distribution and weight gain as risk factors for clinical diabetes in men. Diabetes Care 1994; 17(9): 961-969.

2. Colditz GA, Willett WC, Rotnitzky A, Manson JE. Weight gain as a risk factor for clinical diabetes mellitus in women. Ann Intern Med 1995; 122(7): 481-486.

3. Wald N. Medicines in prevention. In: Wald N, Misselbrook D (eds.). The future of prevention in cardiovascular disease. London: Royal Society of Medicine Press, 2011: 1-15.
4. Gray LJ, Taub NA, Khunti K, et al. The Leicester Risk Assessment score for detecting undiagnosed Type 2 diabetes and impaired glucose regulation for use in a multi-ethnic UK setting. Diabet Med 2010; 27: 887-895.

5. Hippisley-Cox J, Coupland C, Robson J, et al. Predicting risk of type 2 diabetes in England and Wales: prospective derivation and validation of QDScore. BMJ 2009; 338: b880.

6. The Information Centre. Health Survey for England, 2010. London: The NHS Information Centre, UK

\section{Funding}

None.

\section{Provenance}

Freely submitted; externally peer reviewed.

\section{Competing interests}

The authors have received no support from any organisation for the submitted work, have no financial relationships with any organisations that might have an interest in the submitted work, and no other relationships or activities that could appear to have influenced the submitted work.

\section{Acknowledgement}

We thank Kelvin Law for producing the online Beat Diabetes Calculator.

\section{Discuss this article}

Contribute and read comments about this article on the Discussion Forum: http://www.rcgp.org.uk/bjgp-discuss 